\title{
How Does External Knowledge Source Influence Product Innovation In Korean Firms?
}

\author{
Jaegun Lee, Kyungpook National University, South Korea \\ Moon-Goo Huh, Kyungpook National University, South Korea
}

\begin{abstract}
This study addresses how external knowledge sources affect product innovation by examining innovating Korean manufacturers surveyed by STEPI in 2012. The external knowledge source of the company is classified in STI mode (science-technology-innovation) on the basis of scientific knowledge and DUI mode (doing-using-interacting) on the basis of experience knowledge. First, the study reveals that neither the STI nor DUI modes affects the firm's financial performance via product innovation. Second, the results show that the more the company learns from external knowledge through the STI or DUI modes, the more frequent its product innovation. Therefore, STI and DUI usage is found to be proportional to the frequency of product innovation, with the STI mode exerting much more influence on product innovation frequency. Finally, the study finds that neither the STI nor DUI modes affect exploratory innovation but that the DUI mode is proportional to it. Thus, the frequency of product innovation is enhanced through the STI mode via the application of externally sourced scientific knowledge to the innovation process, while current technology and products are enhanced through the DUI mode. This study finds that enhancing product innovation requires that companies determine the proper external knowledge source in accordance with their innovation performance goals.
\end{abstract}

Keywords: Knowledge Search; External Knowledge; STI Mode; DUI Mode; Innovation

\section{PURPOSE OF STUDY}

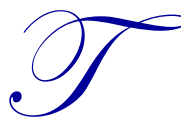

oday's industrial environment is constantly changing, and technology and product lifecycles are shortening. Thus, corporations pursue product innovation to gain a competitive edge in the market. To that end, companies need R\&D capabilities and the ability to utilize external knowledge. Moreover, product innovation is an essential step in ensuring competitiveness and long-term survival (Teece, 2007). Product innovation involves launching new products in the market (Hull and Covin, 2010). Achieving innovation requires a "knowledge search," of which there are two types according to the source location: internal and external search. The former involves sources of knowledge located inside a company, and the latter involves knowledge sources outside it.

There are also two types of innovation activities depending on the source of knowledge. Open innovation occurs using external knowledge and closed innovation through internal knowledge.

Knowledge flow during innovation can be explained from the corporate strategy standpoint. R\&D activities involve both internal and external processes. First, internal R\&D activities make corporate technologies more competitive. Second, external knowledge is acquired in this process. Third, using the acquired knowledge boosts corporate competence (Chohen and Levinthal, 1989). External knowledge is needed for a corporation to acquire knowledge in other areas of technology or to improve its technological or product knowledge (Chohen and Levinthal, 1990). Furthermore, engaging external entities such as suppliers and customers in the innovation process can facilitate innovation (Von Hippel, 1998). Therefore, using external knowledge sources is crucial to successful firm innovation. Given the importance of external knowledge sources, this study explores corporations that perform open innovation. 
When corporations search for external knowledge during open innovation, they explore various sources, such as suppliers, customers, colleges, and research institutes. The context of innovation activities can be divided into the following two types: the STI mode, which is performed on the basis of scientific understanding, and the DUI mode, which obtains solutions to corporate issues based on knowhow and experience (Jensen et al., 2007). The external knowledge sources used in corporate innovation searches have the following characteristics. First, the form of knowledge differs depending on the type of source. Second, the effects of knowledge on innovation can also vary depending on the type of source.

This study examines innovation performance by, first, dividing it into four aspects: financial competence, innovation frequency, exploratory innovation, and exploitative innovation. Second, it determines how external knowledge sources affect each aspect of innovation performance. Third, it explores the effects of multiple external knowledge sources on innovation performance.

This study intends to identify which external knowledge source leads to greater product innovation. Thus, the following research question is posed: How do the effects of external knowledge sources differ depending on the type of innovation performance?

\section{THEORETICAL BACKGROUND}

\section{External Knowledge Sources}

Product innovation can occur through collaboration with external partners, beyond internal R\&D activities (Hull and Covin, 2009). In this process, companies exchange knowledge for innovation (Robertson and Patel, 2007). Actively using external knowledge for innovation can lead to greater innovation performance than would be possible using internal knowledge alone.

The literature posits that two types of learning can occur from external knowledge sources during innovation: the STI (science, technology, innovation) mode and the DUI (doing, using, interacting) mode (Jensen et al., 2007). Each plays different roles in firms' corporate strategies. Their features and effects on innovation performance also vary greatly.

\section{STI Mode}

Innovation through STI is based on scientific understanding during external knowledge searches and firm learning. Here, firms seek knowledge for innovation based on systematic, scientific technology during corporate innovation activities. Thus, the STI mode can be defined as "obtaining scientific knowledge in order to achieve corporate innovation," which leads to an extensive use of information technologies and more attractive innovation knowledge with a modest investment, achieved through knowledge systemization (Lundvall and Lorenz, 2007). The external knowledge sources used include research institutes, universities, consulting firms, and academia. The STI mode uses the scientific knowledge obtained for innovative technology development (Jensen et al., 2007).

The differences between the innovation modes relate to the types of knowledge involved. What the STI and DUI modes obtain through external knowledge sources can be divided depending on whether the knowledge is tacit or explicit (Jensen et al., 2007). The STI mode is conducted explicitly by those seeking solutions to problems. Although some firms have specific knowhow, most corporate knowledge and technologies are generalized or used extensively throughout the same field.

In the STI mode, all results should be documented. It would be unproductive for technology researchers to retain the results through tacit knowledge. Thus, the STI mode gathers external knowledge that can be used extensively if not protected through intellectual property rights. This knowledge can be generalized more easily than can the knowledge gained from the DUI mode and is typically done through patent applications or corporate licensing (Lundvall and Lorenz, 2007). 
Thus, the knowledge acquired through such methods can be systemized, making it more easily deliverable to individuals and corporations (Grant and Baden-Fuller, 2004). The STI mode involves acquiring scientific knowledge, which is more often explicit than tacit. The STI mode allows corporations to gain explicit knowledge while learning through external knowledge. It can be delivered to each corporate member faster than can tacit knowledge and can be applied more effectively (Biery et al., 2009).

\section{DUI Mode}

The main source of knowledge generation since the beginning of the $20^{\text {th }}$ century has been the research institutes of corporations in large industries (Mowery and Oxley, 1995; Chandler, 1997). Even academia now emphasizes external knowledge-based learning, especially through scientific knowledge. However, the importance of tacit knowledge cannot be overlooked. While technological development has occurred through scientific knowledge, the technologies have been used by engineers who only partially understand the technology they are using. A technology must be understood completely for innovation performance to improve, but this understanding is difficult to deliver explicitly (Nelson, 2004).

The DUI mode occurs through problem solving. Employees and executives must solve a wide range of disparate corporate issues; they can do this through the knowledge obtained through the DUI mode. When corporate members face a new issue, most strive to solve it, leading to changes in the organization. As they engage in problem solving, they acquire new knowledge. Thus, the problem-solving process strengthens their knowledge, positively affecting their innovation performance.

The external knowledge obtained through the DUI mode has the following characteristics. First, it is usually informal. Second, it delivers tacit elements that contribute to successful product design launch in line with consumer demand. Third, the knowledge can be obtained from external entities in firms' internal and external supply chains, such as VIP clients, business service providers, competitors, suppliers, and customers (Jensen et al., 2007).

At the same time, the knowledge obtained through DUI is tacit and is related to experience, technology, and knowhow. Thus, it has several drawbacks. First, delivering the knowledge obtained from external sources to a corporation is difficult. Second, it is difficult to integrate this knowledge with a firm's existing knowledge (Kognut and Zander, 1992; Grant and Baden-Fuller, 2004). Nevertheless, this knowledge is more valuable to the maintenance of a firm's competitive edge, as it is difficult for competitors to copy.

Thus, the knowledge gained through the DUI mode is tacit and difficult to acquire externally and apply in a corporation. If applied successfully, however, it can generate greater innovation value.

\section{HYPOTHESES}

\section{Learning from External Knowledge and Innovation Performance}

For corporations to stay competitive, they must secure valuable knowledge and use it actively (Grant, 1996). Using only internal knowledge-based learning without also accepting external knowledge keeps corporations from moving forward and expanding their knowledge. Such limited knowledge makes it difficult for corporations to respond to the changing business environment flexibly (Levitt and March, 1988). Furthermore, studies on open innovation suggest that corporations need to actively acquire external knowledge (Chesborough and Appleyard, 2007). Therefore, corporations must, first, explore market information and external knowledge to achieve innovation. Second, they should actively incorporate the results into their innovation activities. Third, they should acquire information and knowledge from diverse sources, including subsidiaries, competitions, and suppliers. Fourth, they should explore methods of utilizing them effectively (Lee, 2009).

The process of receiving and learning external knowledge has several effects on corporate innovation. First, it allows corporations to improve their products, technologies, and services while also obtaining more diverse and specialized knowledge (Chohen and Levinthal, 1990). Second, innovation performance can be enhanced through the external knowledge acquired. As it comes from more diverse fields than internal knowledge does, the corporate technology and product innovation activities that use external knowledge offer several benefits: they effectively 
reduce the entire innovation process; they offer more ideas and resources; they increase the technological changes in and experimental scope of corporate innovation; and they boost the possibility of product innovation (Fleming, 2001; Katila, 2002; Katila and Ahuja, 2002; Laursen and Salter, 2006). Third, the set of existing technical elements can generate a limited number of new concepts. Therefore, accepting new knowledge from external sources enables corporations to expand the range of technical elements they can use, thus boosting the possibility of making a useful discovery during innovation (Katila and Ahuja, 2002).

Thus, the knowledge and information gained from external sources can help companies respond to the changing business environment, which may be impossible through internal knowledge alone. By applying the acquired knowledge, companies can reduce the steps required for innovation. Accepting knowledge from diverse fields also allows companies to increase the scope of their product innovation, which is then more likely to be achieved. Based on all the above, the following hypothesis is proposed:

H1: Learning through external knowledge is positively related with corporate product innovation.

\section{Learning from External Knowledge and Innovation Frequency}

As discussed, learning through external knowledge can occur in either the STI or DUI mode. The STI mode aims to enhance corporate technology and products based on scientific knowledge that is explicit, systematic, and clear. The knowledge gained through STI makes it easier to deliver external information and knowledge to individuals and corporations (Grant and Baden-Fuller, 2004). Scientific knowledge acquired successfully through external sources can be applied more easily and clearly to corporations than can DUI-mode knowledge (Biery et al., 2009). As the STI mode makes it easier to deliver external knowledge to individuals and corporations, more innovation knowledge can be acquired relatively quickly, thus boosting the frequency of product innovation.

However, innovation activities involve not only scientific knowledge gained through STI but also knowledge from external experience and knowhow, which is gained through the DUI mode and generally consists of tacit knowledge (Jensen et al, 2007). This tacit knowledge is related to experience, skills, and knowhow. Therefore, it is not systemized, as it is not generated through accumulated learning experience. Since it is not documented, it is more difficult to deliver to others than is STI-mode knowledge. However, it offers an important benefit: as it is difficult for competitors to copy, the knowledge gained through the DUI mode is more valuable and helps corporations maintain their competitive advantage. However, it also has drawbacks. First, it is difficult to integrate with a firm's existing knowledge. Second, it is difficult to obtain and apply the knowledge (Kogut and Zander, 1992). Third, the DUI mode makes it difficult to deliver the external knowledge to individuals and corporations, unlike the STI mode. Thus, it is less likely to be applied. As a result, acquiring external knowledge through DUI has less of an effect on the frequency of product innovation. Based on the above, the following hypothesis is proposed.

H2: Acquiring external knowledge through the STI mode has a greater effect on the frequency of product innovation than does DUI-mode acquisition.

\section{Learning from External Knowledge and Exploratory/Exploitative Innovation}

Two types of product innovation can occur, distinguished according to the new products' features: exploratory innovation and exploitative innovation. The types differ in two key ways. First, they use different resources, knowledge, and abilities to achieve the innovation. Second, the innovations' goals, natures, and approaches differ, giving them different characteristics (Park, Lee, 2008). Exploratory innovation is achieved when corporations focus on developing innovative products with new functions or performance characteristics rather than improving existing products (Levinthal and March, 1993). Exploitative innovation is achieved by utilizing firm market and technical knowledge. Along with this knowledge, production experience is also used for product development. The overall aim is to enhance current product performance or quality (March, 1991).

Companies pursuing open innovation that adopt ideas or resources from external knowledge sources can increase their technological changes and experimental scope, increasing opportunities for product innovation (Fleming, 2001; Katila, 2002; Katila and Ahuja, 2002; Laursen and Salter, 2006). Increasing the number of potential concepts that can be generated through the technical elements acquired through STI learning increases the possibility of making 
discoveries useful for product innovation, allowing corporations to develop more new products. Thus, gaining external knowledge through STI will have a greater effect on product innovation than will the DUI process. However, gaining external knowledge through DUI is useful for solving current issues, as it allows firms to learn from the experience and knowhow of others. As this mode focuses on solving problems through external experience, DUI is ideal for improving current issues concerning technologies or product quality and performance. Gaining external knowledge through the DUI mode therefore has a greater effect on exploitative innovation than does the STI-mode process. Based on the above, the following hypotheses are proposed:

H3-a: Acquiring external knowledge through the STI mode has a greater effect on exploratory innovation than does the DUI-mode process.

H3-b: Acquiring external knowledge through the DUI mode has a greater effect on exploitative innovation than does the STI-mode process.

\section{METHOD OF STUDY}

\section{Sample}

Data from the 2012 Korean Innovation Survey (KIS) were used for analysis. The survey, designed and conducted by the Science and Policy Technology Institute (STEPI), is based on the Oslo Manual developed and supplied by the OECD and the EU's Eurostat Community Innovation Survey (CIS). The survey's statistics were approved by the National Statistical Office, indicating their strong reliability, suitability, and international comparability.

This study was conducted on domestic manufacturers pursuing innovation through external knowledge sources in knowledge-based industries. Corporations that failed to respond to all input variables were excluded because this study is intended to explore how corporations pursuing open innovation acquire external knowledge and use it to achieve innovation. Only companies that had been operating for more than five years were examined because startup effects could have undermined the accuracy of the results (Moon-Goo Huh, 2011). A total of 164 companies were selected as the final sample.

\section{Operationalizing Variables}

\section{Dependent Variables}

This study uses "innovation performance" as a dependent variable. It was operationalized as the proportion of products developed in the last three years to total sales in 2011, following prior studies. The products developed within the last three years can be divided into three types: new products, greatly improved products, and other products. In the KIS (2012), however, product innovation is limited to new products and greatly improved products. Thus, these two types were combined and operationalized as "innovation performance."

Frequency of innovation was measured as the number of patents registered in connection with product innovation from 2009 to 2011. Patent data have the following limitations: there are differences among the tendencies of the patent applications depending on the industry, and patents are valuable only when they become profitable through commercialization (Moon-Goo Huh, 2011). However, patent applications were deemed to be the best indicators of innovation frequency in the KIS survey.

There are two types of product innovation: exploratory and exploitative. The former was studied among companies that had launched completely different products. Exploratory innovation was measured as the proportion of new products to total 2011 sales. Exploitative innovation, studied among companies that had launched greatly improved products, was measured as the proportion of those products to total 2011 sales. 


\section{Independent Variables}

The external knowledge sources of the independent variables were divided into STI mode and DUI mode, following prior studies (Jensen, 2007). Using the KIS (2012), the following were operationalized as the external knowledge sources of the DUI mode: suppliers, clients, associations, cooperatives, external meetings, competitors, and other companies in the same industry. The following were operationalized as the external knowledge sources of the STI mode: private service providers, higher education institutions (i.e., college or above), government or public research institutes, conferences, fairs, exhibitions, and specialized journals and books.

Each variable indicates the importance of the knowledge sources included (i.e., the mean value). A company's internal information was omitted as an internal knowledge source.

\section{Control Variables}

To verify the independent variables' effects on the dependent variables, the following factors were used as control variables following prior studies: firm size, firm age, $R \& D$ intensity, proportion of internal $R \& D$, scale of innovation activities, and the differences across industries.

The variables were selected for the following reasons. First, firm size indicates differences among levels of resource possession. Thus, the number of employees was converted into a natural logarithm for control purposes. Second, R\&D intensity can have a significant effect on innovation. Thus, the number of employees engaged in R\&D was controlled as "R\&D intensity" for measurement. Third, the proportion of internal R\&D can influence corporation innovation, aside from the effect of external knowledge sources. Since it can distort the innovation performance achieved through external knowledge, this variable was controlled. Fourth, the scale of innovation activities is the combined costs of internal and external innovation activities. Since these costs can affect innovation performance, this variable was controlled. Fifth, within knowledge-based industries, levels of external knowledge acquisition differ depending on industry characteristics, which could significantly affect innovation performance. Thus, the following seven industries were controlled as dummy variables: metals and processing, machinery and equipment, medical and precision apparatus, automobiles, electrical equipment, electronics, sound equipment, telecommunication, and chemicals.

Table 1. Pearson's correlation of the variables

\begin{tabular}{|c|c|c|c|c|c|}
\hline & $\begin{array}{c}\text { Innovation } \\
\text { performance }\end{array}$ & $\begin{array}{c}\text { Innovation } \\
\text { frequency }\end{array}$ & $\begin{array}{c}\text { Exploratory } \\
\text { innovation }\end{array}$ & $\begin{array}{c}\text { Exploitative } \\
\text { innovation }\end{array}$ & Firm age \\
\hline Innovation performance & 1.0000 & & & & \\
\hline Innovation frequency & -0.0672 & 1.0000 & & & \\
\hline Exploratory innovation & 0.0570 & $0.1392^{*}$ & 1.0000 & & \\
\hline Exploitative innovation & -0.001 & 0.0376 & $-0.5609^{* * *}$ & 1.0000 & \\
\hline Firm age & -0.0936 & 0.0223 & 0.0045 & 0.0101 & 1.0000 \\
\hline Firm size & -0.0590 & $0.3676^{* * *}$ & $0.16^{* *}$ & -0.1089 & $0.5029^{* * *}$ \\
\hline Innovation size & 0.0805 & $0.2014^{* *}$ & 0.0220 & 0.0581 & $0.2225^{* * *}$ \\
\hline R\&D Intensity & 0.0390 & $0.1623^{* *}$ & -0.0276 & -0.0087 & $0.2574^{* * *}$ \\
\hline Internal R\&D & $-0.1457^{*}$ & 0.0821 & 0.0255 & -0.0543 & 0.0722 \\
\hline STI mode & 0.0522 & $0.1734^{* *}$ & 0.0922 & -0.0074 & 0.0682 \\
\hline DUI mode & 0.0149 & $0.0387^{* *}$ & -0.0406 & 0.1289 & -0.0191 \\
\hline
\end{tabular}


(Table 1 continued)

\begin{tabular}{|c|c|c|c|c|c|c|}
\hline & Firm size & $\begin{array}{c}\text { Innovation } \\
\text { size }\end{array}$ & $\begin{array}{c}\text { R\&D } \\
\text { Intensity }\end{array}$ & $\begin{array}{c}\text { Internal } \\
\text { R\&D }\end{array}$ & STI mode & DUI mode \\
\hline \multicolumn{7}{|c|}{ Innovation performance } \\
\hline \multicolumn{7}{|c|}{ Innovation frequency } \\
\hline \multicolumn{7}{|c|}{ Exploratory innovation } \\
\hline \multicolumn{7}{|c|}{ Exploitative innovation } \\
\hline \multicolumn{7}{|c|}{ Firm age } \\
\hline Firm size & 1.0000 & & & & & \\
\hline Innovation size & $0.4276^{* * *}$ & 1.0000 & & & & \\
\hline R\&D Intensity & $0.3339^{* * *}$ & $0.5273^{* * *}$ & 1.0000 & & & \\
\hline Internal R\&D & 0.0408 & -0.0394 & 0.0486 & 1.0000 & & \\
\hline STI mode & $0.1957^{* *}$ & 0.0930 & 0.0918 & $-0.1765^{* *}$ & 1.0000 & \\
\hline DUI mode & 0.0001 & -0.0225 & -0.0075 & -0.1089 & $0.3063^{* * *}$ & 1.0000 \\
\hline
\end{tabular}

${ }^{*} \mathrm{p}<.05, * * \mathrm{p}<.01, * * * \mathrm{p}<.001$

Table 2. Result of Tobit analysis for innovation performance

\begin{tabular}{|c|c|c|c|c|}
\hline & 1 & 2 & 3 & 4 \\
\hline Firm age & $0.14(0.36)$ & $0.15(0.36)$ & $0.14(0.36)$ & $0.15(0.36)$ \\
\hline Firm size & $-4.36(2.79)$ & $-4.91(2.85)$ & $-4.37(2.89)$ & $-4.94(2.85)$ \\
\hline Innovation size & $0.00(0.00)$ & $0.00(0.00)$ & $0.00(0.00)$ & $0.00(0.00)$ \\
\hline R\&D Intensity & $0.01(0.01)$ & $0.01(0.01)$ & $0.01(0.01)$ & $0.01(0.01)$ \\
\hline Internal R\&D & $-0.20(0.10)^{*}$ & $-0.18(0.10)$ & $-0.20(0.10)^{*}$ & $-0.18(0.10)$ \\
\hline Industrial dummy & include & include & include & include \\
\hline STI_mode & & $4.96(4.70)$ & & $5.29(4.95)$ \\
\hline DUI_mode & & & $0.48(3.72)$ & $-0.83(3.90)$ \\
\hline Log likelihood & -757.96265 & -757.40712 & -757.9542 & -757.38478 \\
\hline Prob $>$ chi 2 & 0.1358 & 0.1402 & 0.1840 & 0.1859 \\
\hline Pseudo R2 & 0.0105 & 0.0113 & 0.0105 & 0.0113 \\
\hline
\end{tabular}

Values are unstandardized coefficients, with standard errors in parentheses. ${ }^{*} \mathrm{p}<.05,{ }^{*} \mathrm{p}<.01,{ }^{* * *} \mathrm{p}<.001$

Table 3. Result of Poisson distribution for innovation frequency

\begin{tabular}{l|c|c|c|c}
\hline & 1 & 2 & 3 & 4 \\
\hline Firm age & $-0.02(0.00)^{* * *}$ & $-0.02(0.00)^{* * *}$ & $-0.02(0.00)^{* * *}$ & $-0.02(0.00)^{* * *}$ \\
\hline Firm size & $0.79(0.03)^{* * *}$ & $0.73(0.03)^{* * *}$ & $0.80(0.03)^{* * *}$ & $0.74(0.03)^{* * *}$ \\
\hline Innovation size & $0.00(0.00)^{* *}$ & $0.00(0.00)$ & $0.00(0.00)^{* *}$ & $0.00(0.00)$ \\
\hline R\&D Intensity & $-0.00(0.0)^{* * *}$ & $-0.00(0.0)^{* * *}$ & $-0.00(0.0)^{* * *}$ & $-0.00(0.0)^{* * *}$ \\
\hline Internal R\&D & $0.01(0.00)^{* * *}$ & $0.01(0.00)^{* * *}$ & $0.01(0.00)^{* * *}$ & $0.01(0.00)^{* * *}$ \\
\hline Industrial dummy & include & include & include & include \\
\hline STI mode & & $0.41(0.05)^{* * *}$ & & $0.35(0.05)^{* * *}$ \\
\hline DUI mode & & & $0.27(0.05)^{* * *}$ & $0.17(0.05)^{* * *}$ \\
\hline Log likelihood & -872.18189 & -839.54757 & -855.22993 & -833.16062 \\
\hline Prob > chi2 & 0.0000 & 0.0000 & 0.0000 & 0.0000 \\
\hline Pseudo R2 & 0.4717 & 0.4915 & 0.4820 & 0.4953 \\
\hline \multicolumn{1}{|c|}{ Valus are } & & & \\
\hline
\end{tabular}

Values are unstandardized coefficients, with standard errors in parentheses. ${ }^{*} \mathrm{p}<.05,{ }^{* *} \mathrm{p}<.01,{ }^{* * *} \mathrm{p}<.001$

\section{RESULTS}

Table 1 indicates the Pearson's correlation of the variables used in this study. First, exploratory innovation and exploitative innovation, the dependent variables, are negatively correlated, reflecting the characteristics of exploration and exploitation (i.e., utilization). Second, firm size and age are positively correlated. Third, the total costs of innovation activities and corporate size are positively correlated. Fourth, R\&D intensity is highly correlated with the total costs of innovation activities. 
In testing the first hypothesis, Tobit regression analysis was used to prevent an overestimation of coefficients arising from general regression analysis, as the innovation performance values range from 0 to 100 and have two cut-off values. The statistical package used in the analysis was STATA 11.2. Hypotheses 2 and 3 were tested through Poisson distribution and Probit analysis respectively. In Hypothesis 2, innovation frequency, a dependent variable, is a count variable. Thus, Poisson distribution was used. The exploratory innovation and exploitative innovation variables are binary (i.e., 0 and 1). Thus, Probit analysis was used.

The Probit analysis results for Hypothesis 1 appear in Table 2. Model 1 verified the effects of the control variables; internal $R \& D$ had a negative effect on product innovation performance $(\mathrm{p}<.05)$. Model 2 verified the effects of the STI mode on product innovation; STI mode had no significant effect on product innovation performance. Model 3 verified the effects of the DUI mode on product innovation; DUI mode also had no significant effect. Model 4 verified the overall effects of the STI and DUI modes; neither one had a significant effect. Thus, Hypothesis 1 was not supported, as the table indicates.

Table 3 shows the Poisson distribution of product innovation frequency. As the table indicates, firm age $(\mathrm{p}<.001)$ and R\&D size $(\mathrm{p}<.001)$ had negative effects on product innovation frequency $(\mathrm{p}<.001)$. However, firm size $(p<.001)$, total costs of innovation activities $(p<.01)$, and internal $R \& D$ all had positive effects.

Model 2 shows the relation between product innovation frequency and STI mode; there was a significantly positive relation between STI mode and innovation frequency $(\mathrm{p}<.001)$. Model 3 shows the relation between product innovation frequency and DUI mode; there was also a significantly positive relation between DUI mode and innovation frequency $(\mathrm{p}<.001)$. Model 4 is an integrated model with the two types of external knowledge sources both the STI and DUI modes have significantly positive effects on innovation frequency.

To test the hypothesis that STI mode has a greater effect on product innovation frequency than does the DUI mode, it would be statistically meaningless to identify the influence of each variable through coefficients in the result values. To compare the influences accurately, IRR (incidence-rate ratio) values were analyzed. The IRR values make it possible to compare two variables through their occurrence ratios in the Poisson distribution. The analysis results are shown in Table 4. The IRR value of the STI mode was $1.424037(\mathrm{p}<.001)$, greater than the DUI mode's value of $1.183019(\mathrm{p}<.001)$. Thus, the STI mode had a greater effect on product innovation frequency than did the DUI mode. This result supported Hypothesis 2.

Table 5 shows the effects of acquiring external knowledge on exploratory innovation. To identify the effects, Probit analysis was used. In all the models (1, 2, 3, and 4), firm size was positively related with exploratory innovation $(\mathrm{p}<.01)$. However, Model 2 shows that the STI mode had no statistically significant effect on exploratory innovation, as is the case with the DUI mode. Therefore, Hypothesis 3-a was not supported.

To verify the effects of exploitative innovation, Probit analysis was used again. Table 6 reports the findings. Model 1 verified the effects of the control variables on exploitative innovation; there were no significant values. Model 2 verified the effects of STI mode on exploitative innovation; these values were also statistically insignificant. Thus, STI mode was not related to exploitative innovation.

Model 3 verified the effects of DUI mode on exploitative innovation, showing that DUI mode was positively related with exploitative innovation $(\mathrm{p}<.05)$. Model 4 , an integrated mode including all the variables, showed that DUI mode was positively related with exploitative innovation $(\mathrm{p}<.05)$. Therefore, the hypothesis that the DUI mode has a greater effect on exploitative innovation than does the STI mode produced the following results: Hypothesis 3-b was supported because the STI mode had no significant values, while the DUI mode had a positive relation. Therefore, Hypothesis 3 was partially supported. 
Table 4. Result of incidence-rate ratio for $\mathrm{H} 2$

\begin{tabular}{|c|c|c|c|c|}
\hline & IRR & standard error & $Z$ - value & P-value \\
\hline STI mode & 1.424037 & 0.08 & 6.69 & 0.000 \\
\hline DUI mode & 1.183019 & 0.06 & 3.58 & 0.000 \\
\hline
\end{tabular}

Table 5. Result of Probit analysis for Exploratory innovation

\begin{tabular}{|c|c|c|c|c|}
\hline & 1 & 2 & 3 & 4 \\
\hline Firm age & $-0.01(0.01)$ & $-0.01(0.01)$ & $-0.01(0.01)$ & $-0.01(0.01)$ \\
\hline Firm size & $0.36(0.11)^{* *}$ & $0.38(0.12)^{* *}$ & $0.37(0.11)^{* *}$ & $0.37(0.12)^{* *}$ \\
\hline Innovation size & $-0.00(0.00)$ & $-0.00(0.00)$ & $-0.00(0.00)$ & $-0.00(0.00)$ \\
\hline R\&D Intensity & $-0.00(0.0)$ & $-0.00(0.0)$ & $-0.00(0.0)$ & $-0.00(0.0)$ \\
\hline Internal R\&D & $-0.001(0.002)$ & $-0.002(0.003)$ & $-0.001(0.003)$ & $-0.002(0.003)$ \\
\hline Industrial dummy & include & include & include & include \\
\hline STI mode & & $-0.11(0.17)$ & & $-0.03(0.50)$ \\
\hline DUI mode & & & $-0.19(0.13)$ & $-0.18(0.14)$ \\
\hline Log likelihood & -102.39994 & -102.1856 & -101.39062 & -101.37264 \\
\hline Prob > chi 2 & 0.2023 & 0.2407 & 0.1651 & 0.2163 \\
\hline Pseudo R2 & 0.0665 & 0.0684 & 0.0757 & 0.0758 \\
\hline
\end{tabular}

Values are unstandardized coefficients, with standard errors in parentheses. ${ }^{*} \mathrm{p}<.05,{ }^{* *} \mathrm{p}<.01,{ }^{* * *} \mathrm{p}<.001$

Table 6. Result of Probit analysis for Exploitative innovation

\begin{tabular}{l|c|c|c|c}
\hline & 1 & 2 & 3 & 4 \\
\hline Firm age & $0.00(0.01)$ & $0.00(0.01)$ & $0.00(0.01)$ & $0.00(0.01)$ \\
\hline Firm size & $-0.17(0.10)$ & $-0.19(0.10)$ & $-0.16(0.11)$ & $-0.17(0.11)$ \\
\hline Innovation size & $0.00(0.00)$ & $0.00(0.00)$ & $0.00(0.00)$ & $0.00(0.00)$ \\
\hline R\&D Intensity & $-0.00(0.00)$ & $-0.00(0.00)$ & $-0.00(0.00)$ & $-0.00(0.00)$ \\
\hline Internal R\&D & $0.00(0.00)$ & $0.00(0.00)$ & $0.00(0.00)$ & $0.00(0.00)$ \\
\hline Industrial dummy & include & include & include & include \\
\hline STI mode & & $0.22(0.17)$ & & $0.10(0.19)$ \\
\hline DUI mode & & & $0.33(0.14)^{*}$ & $0.31(0.15)^{*}$ \\
\hline Log likelihood & -97.271841 & -96.507137 & -94.423841 & -94.294212 \\
\hline Prob $>$ chi2 & 0.0696 & 0.0656 & 0.0188 & 0.0268 \\
\hline Pseudo R2 & 0.0871 & 0.0942 & 0.1138 & 0.1150 \\
\hline Vas & & & & \\
\hline
\end{tabular}

Values are unstandardized coefficients, with standard errors in parentheses. ${ }^{*} \mathrm{p}<.05,{ }^{* *} \mathrm{p}<.01,{ }^{* * *} \mathrm{p}<.001$

\section{CONCLUSION}

This study has investigated the external knowledge acquisition of domestic manufacturers. Two different types of external knowledge sources were considered, and the effects of each source on corporate innovation were explored. The study found that, first, external knowledge sources had no significant effect on product innovation relative to total sales. Second, acquiring external knowledge through the STI and DUI modes increased the frequency of product innovation, and the STI mode had the greater effect. Third, neither mode had a significant effect on exploratory product innovation. Fourth, the DUI mode had a significant effect on exploitative product innovation.

This study therefore proved that the effects of external knowledge sources on product innovation vary depending on the type of source. Most studies have explored the effects of the STI and DUI modes on product and process innovation. However, their effects on product innovation and its sub-variables have never been studied. Moreover, though many studies have identified the relation between the STI mode and product innovation, studies on the DUI mode have found only that it has a minimal effect on product innovation and significant effects on process innovation. This study has verified that the DUI mode has a significant effect on exploitative product innovation.

These findings have implications for corporate management. To achieve product innovation, corporations should choose external knowledge sources aligned with their goals. In particular, they should remember that, first, scientific knowledge has no effect either on exploratory innovation or on exploitative innovation. However, scientific 
knowledge has a positive effect on product innovation. Second, acquiring external knowledge via DUI has a positive effect on product innovation frequency. However, the managers of small companies selecting from among limited available resources must make the right decision for improving their product innovation performance.

This study has verified the effects of external knowledge sources on product innovation performance using a statistical approach based on the KIS 2012 of the STEPI. As with any study based on similar data, this one has several limitations. First, there was no direct intervention in the respondents or their responses, which limits the empirical model. Specifically, each question may have been answered by employees in different positions with different duties. Moreover, one employee from each corporation may have answered all the questions. Thus, the results may have a common method bias, which would be hard to eliminate given the characteristics of this study. Second, measuring the variables in the KIS data probably involved only one question for each variable. Although multiple questions were used to measure the independent variables, only one question was used to measure the control and dependent variables.

Future studies could address these limitations in several ways. First, this study has established the following as subvariables of product innovation performance: financial aptitude, product innovation frequency, and exploratory/exploitative product innovation. However, these sub-variables could be expanded, such as into "novelty of innovation" or "innovation life," using KIS data. Diverse sub-variables should be used to identify the roles of the STI and DUI modes in product innovation in more depth. Second, this study has identified the effects of each external knowledge source on product innovation. However, Jensen et al. (2007) found that using two different sources rather than just one is more effective in boosting innovation possibility. Therefore, how the interaction of more than one external knowledge source influences product innovation should be explored by the sub-variable. Third, this study has focused on product innovation. However, the information and knowledge from external sources can be used in other types of innovation, such as process and organizational innovation. Therefore, the effects of external knowledge sources on different types of innovation should also be examined by the sub-variable.

\section{ACKNOWLEDGEMENTS}

This work was supported by the Ministry of Education of the Republic of Korea and the National Research Foundation of Korea (NRF-2015S1A5A2A01011498).

\section{AUTHOR BIOGRAPHIES}

Jaegun Lee is an Ph.D. student at the School of Business Administration, Kyungpook National University, Korea. He earned his MA in strategy and organization from the School of Business Administration, Kyungpook National University, Korea. His research interests include external knowledge, firm innovation, and innovation failure. E-mail: hl6ylz@gmail.com (First author)

Moon-Goo Huh, (Ph.D. Korea University) is a professor of strategy and organization at the School of Business Administration, Kyungpook National University, Korea. His current research interests include firm innovation, exploration and exploitation, modes of ambidexterity, strategic and organizational change, knowledge creation, and social capital. He has authored four books, and published over 30 research articles in domestic and international peer-reviewed journals. He served as a president of the Korean Society of Strategic Management. E-mail: moongoo@knu.ac.kr (Corresponding author)

\section{REFERENCES}

Almirall \& Masanell. 2010. Open verse closed innovation: a model of discovery and divergence. Academy of Management Review, 35(1): 27-47.

Bierly, Damanpour, Santoro. 2009. The application of external knowledge: organizational conditions for exploration and exploitation. Journal of Management Studies, 46(3): 481-509.

Chai, Choi, Huh. 2014. Open Innovation in Venture Firms: the Impact of External Search Strategy on Innovation Performance of Korean Manufacturing Firms. The Journal of Business Venturing and Entrepreneurship, 9(1): 1-13.

Chesbrough \& Crowther. 2006. Beyond high tech: early adopters of open innovation in other industries. R\&D Management, 36(3): 229 236. 
Clausen, Korneliussen, Madsen. 2013. Modes of innovation, resources and their influence on product innovation: Empirical evidence from R\&D active firms in Norway. Technovation, 33: 223-233.

Cockburn \& Henderson. 1998. Absorptive capacity, coauthoring behavior, and the organization of research in drug discovery. The Journal of Industrial Economics, 46(2): 157-182.

Cohen \& Levinthal. 1990. Absorptive capacity: A new perspective on learning and innovation. Administrative Science Quarterly, 35: 128-138.

Espallardo, Pe'rez, Lo'pez. 2011. Exploitation- and exploration-based innovations: The role of knowledge in inter-firm relationships with distributors. Technovation, 31: 203-215.

Fitjar \& Pose. 2013. Firm collaboration and modes of innovation in Norway. Research Policy, 42: 128-138.

Fleming \& Sorenson. 2001. Technology as a complex adaptive system: evidence from patent data. Research Policy, 30: 10191039.

Grant. 1996. Toward a knowledge-based theory of the firm. Strategic Management Journal, 17: 109-122.

Grant \& Fuller. 2004. A knowledge accessing theory of strategic alliances. Journal of Management Studies, 41(1): 61-83.

He \& Wong. 2004. Exploration vs. Exploitation: an empirical test of the ambidexterity hypothesis. Organization Science, 15(4): 481-494.

Huh. 2011. Knowledge search and innovation. Korean Management Review, 40(5): 1247-1271.

Hull \& Covin. 2010. Learning capability, technological parity, and innovation mode use. Product Bevelopment\&Mangement Association, 27: 97-114.

Jensen et al. 2007. Forms of knowledge and modes of innovation. Research Policy, 36: 680-693.

Kale, Singh, Perlmutter. 2000. Learning and protection of proprietary assets in strategic alliance: building relational capital. Strategic Management Journal, 21: 217-237.

Katila \& Ahuja. 2002. Something old, something new: a longitudinal study of search behavior and new product introduction. Academy of Management Journal, 45: 1183-1194.

Kirner, Kinkel, Jaeger. 2009. Innovation paths and the innovation performance of low-technology firms-An empirical analysis of German industry. Research Policy, 38: 447-458.

Kogut \& Zander. 1992. Knowledge of the firm, combinative capabilities, and the replication of technology. Organization Science, 3(3): 383-397.

Laursen \& Salter. 2006. Open for innovation: the role of openness in explaining innovation performance amog U.K manufacturing firms. Strategic Management Journal, 27: 131-150.

Lee. 2009. Utilization of knowledge base and its requisites for the performance of innovation using external knowledge. Knowledge Management Research, 10(4): 75-91.

Lee, Chae, Suh. 2003. Using of external knowledge based on knowledge classification. The e-Business Studies, 4(2): 53-76.

Levitt \& March. 1988. Organizational learning. Annual Review of Sociology, 14: 319-340.

Levitt \& March. 1993. The myopia of learning. Strategic Management Journal, 14: 95-112.

Lichtenthaler \& Lichtenthaler. 2009. A capability-based framework for open innovation: complementing absorptive capacity. Journal of Management Studies, 46(8): 1315-1338.

Lundvall \& Lorenz. 2007. Modes of innovation and knowledge taxonomies in the learning economy. CAS workshop in Innovation in Firms, 1-22.

March. 1991. Exploration and exploitation in organizational learning. Organization Science, 2(1): 71-86.

Park \& Lee. 2008. The impact of exploration, exploitation, and R\&D organization on innovations in the Korean SMEs. Korea Technology Innovation Society, 11(1): 118-143.

Park et al. 2007. Causes and remedies of common method bias. Korean Academy of Management, 15(1): 89-133.

Robertson \& Patel. 2007. New wine in old bottles: Technological diffusion in developed economies. Research Policy, 36: 708721.

Rosenkopf \& Nerkar. 2001. Beyond local search: boundary-spanning, exploration, and impact in the optical disk industry. Strategic Management Journal, 22: 287-306.

Teece. 2007. Explicating dynamic capabilities: the nature and microfoundations of (sustainable)enterprise performance. Strategic Management Journal, 28(13): 1319-1350.

Urban and Hippel. 1988. Lead user analyses for the development of new industrial products. Management Science, 34(5): 569-58 


\section{NOTES}

